\title{
Processos interativos em sala de aula de jovens e adultos: a utilização do livro didático em questão
}

\author{
Interactive processes of the youth and adult \\ classroom: the use of the didactic book in question
}

Marinaide Lima de Queiroz FREITAS

Tania Maria de MOURA

\begin{abstract}
RESUMO
Neste texto serão apresentados os resultados da investigação que teve como foco analisar a utilização do Livro Didático - LD no processo interativo de sala de aula da $1^{\mathrm{a}}$ Fase da Educação de Jovens e Adultos - EJA. A opção metodológica centrou-se na abordagem da pesquisa qualitativa na modalidade do Estudo de Caso auxiliado pelas orientações da etnografia interacional. Para fundamentar a pesquisa tomou-se como referencial teórico os estudos de Bakhtin (2004), Geraldi (2002), Koch (1997), Marcuschi (2001), Bazerman (2006). A pesquisa revelou dentre outros aspectos que o uso do LD, não é uma prática constante em sala de aula, outros suportes de gêneros como jornais e revistas marcam presença. Revelou também que não foi explorada e nem valorizadas outras vozes presentes nos gêneros trabalhados, tanto do LD como de outros suportes, prejudicando assim, o entendimento ao enfoque bakhtiniano, fazendo com que a interação e, conseqüentemente, a interação verbal não acontecessem amplamente.
\end{abstract}

Palavras-chave: Educação de Jovens e Adultos, livro didático, língua materna, interação. 


\begin{abstract}
In this text will be presented the conclusions of the research that the objective it was to analyse the usage of the Schoolbook, in the interactive process of classroom in $1^{\text {a }}$ Stage of the Youth and Adult Education. The methodological option was centered in a qualitative analysis and in a case study with the orientations of the interactional ethnography. This study it was documented in the research literature Bakhtin (2004), Geraldi (2002), koch (1997), Marcuschi (2001), Bazerman (2006). The research presented that, among different conclusions, the Schoolbook, it wasn't a constant practice in the classroom, another supports of the same kind like newspapers and magazines mark their presence. It also exposed that it wasn't explored neither valued another aspects present in the this kind of supports, as the Didactic Book as another supports, prejudicing in this way, the understanding of the perspective bakhtiniano, making that the interaction and, consequently, the verbal interaction do not happen amply.
\end{abstract}

Index terms: Youth and Adult Education, Schoolbook, Verbal interaction, Interaction.

\title{
Considerações Iniciais
}

O texto apresentado constitui-se em um recorte de pesquisa ${ }^{1}$ intitulada "O livro didático em sala de aula: análise da utilização no processo interativo de sala de aula do Primeiro Segmento do Ensino Fundamental da Educação de Jovens e Adultos”.

A investigação foi norteada pelo problema: Como os gêneros textuais constantes nos Livros Didáticos de EJA são utilizados lingüisticamente, pelos alunos e professores na sala de aula? A formulação do problema, tendo como foco o processo ensino-aprendizagem constituído

\footnotetext{
${ }^{1}$ Pesquisa financiada pelo PIBIC-CNPq.
} 
por alunos e professores em torno do LD de Língua Materna, foi motivada pelos seguintes questionamentos: Qual o lugar que o LD ocupa na prática pedagógica no ensino da escrita na EJA? Como se configuram as interações mediadas pelos LDs? A interação face a face propicia o andamento do processo ensino-aprendizagem da escrita, no LD da EJA? Como o discurso é instituído nesse espaço interacional? Que vozes o LD faz circular nesse espaço? Os alunos e professores conseguem se apropriar de conceitos básicos de gêneros, tipos textuais e domínios discursivos que alterarão seus comportamentos e habilidades frente ao letramento escolar e a prática social?

Para responder as questões a pesquisa teve como objetivo geral: Analisar as situações de sala de aula ${ }^{2}$ em que os jovens e adultos em processo de alfabetização vivenciam a produção dos gêneros textuais constantes no LD de EJA.

A pesquisa que deu origem ao texto foi de natureza qualitativa. Para sua realização recorreu-se ao estudo de caso e as orientações da etnografia interacional. O estudo de caso é caracterizado por Gil (1991, p. 58) como um “[...] estudo profundo e exaustivo de ou de poucos objetos, de maneira que permita o seu amplo e detalhado conhecimento [...]”.

A etnografia interacional possibilitou a realização de um trabalho interpretativo e observacional que acompanhou o dinamismo dos elementos observados e dos fenômenos textuais. Para Nunes-Macedo et al (2004) através das orientações da etnografia interacional, pesquisadores têm investigado as interações em sala de aula partindo do pressuposto de que essa é uma “comunidade culturalmente constituída” por meio da participação de diferentes sujeitos, que assumem diferentes papéis no processo de ensino-aprendizagem. Nessa perspectiva, a aprendizagem é definida situacionalmente por meio das formas em que professores e alunos

\footnotetext{
2 Entende-se sala de aula no sentido defendido por Macedo (et al, 2004, p. 18-19): como uma comunidade culturalmente constituída por meio da participação de diferentes sujeitos, que assumem diferentes papéis no processo ensino aprendizagem.
} 
constróem os padrões e práticas da vida de cada sala de aula (op. cit., idem, p. 18-19).

As abordagens metodológicas foram auxiliadas pelos procedimentos:

a) levantamento bibliográfico, seleção e estudo das categorias norteadoras da pesquisa: gêneros textuais, interação, escrita, concepções de linguagem, livro didático, dentre outras; b) entrevistas - gravadas em fitas cassete - com as professoras da $1^{\mathrm{a}}$ e $3^{\mathrm{a}}$ fases do Ensino Fundamental de $\mathrm{EJA}^{3}$, de uma escola pública municipal; c) aplicação de questionário com as professoras e com os seus alunos; d) observação de treze (13) eventos de letramento de aulas de Língua Materna - LM, na sala de aula da $1^{\text {a }}$ fase e 07 (sete) eventos na $3^{\mathrm{a}}$ fase.

A observação dos eventos de letramento das aulas de LM priorizou os padrões que caracterizam a interação professor/aluno ou evento de fala específico em uma determinada comunidade de fala. Os referidos eventos foram devidamente organizados em mapas de letramento e analisados. Todo corpora obtido através da entrevista, do questionário e da observação das aulas, foram tabulados e analisados a luz da fundamentação teórica estudada. Apresenta-se nesse texto o recorte da análise do corpora obtido na investigação realizada com a $1^{\text {a }}$ fase (alfabetização) do I segmento da EJA.

Os resultados das análises serão explicitados a partir de três blocos de interpretação: A) caracterização da escola e caracterização dos sujeitos investigados - professora e aluno(a)s; B) as representações ${ }^{4}$ que a professora e aluno(a)s da $1^{\mathrm{a}}$ fase apresentaram sobre o LD e a sua utilização; C) a constituição das interações das aulas considerando a ação/evento de letramento desenvolvido que possibilitou o trabalho individual e coletivo com o LD.

\footnotetext{
${ }^{3}$ Na realidade investigada a Educação de Jovens e Adultos é ofertada apenas para o I Segmento do Ensino Fundamental e organiza-se em três fases: A $1^{\mathrm{a}}$ fase corresponde à alfabetização; a $2^{\mathrm{a}}$ fase as $1^{\mathrm{a}} \mathrm{e} 2^{\mathrm{a}}$ séries; a $3^{\mathrm{a}}$ fase às $3^{\mathrm{a}} \mathrm{e} 4^{\mathrm{a}}$ séries.

${ }^{4}$ Denominaram-se representações, na pesquisa, as opiniões, conceitos e concepções da professora e dos alunos investigados.
} 


\section{A Escola locus da investigação}

A Escola surgiu a partir do funcionamento de um Centro Comunitário, em fevereiro de 1994, com cursos de geração de renda para a população do bairro, além de outros como: culinária, pintura, reciclagem em

geral, crochê e tricô, envolvendo mais as mulheres. Os produtos advindos dos cursos eram vendidos na frente do próprio prédio, com o objetivo de se obter um fundo financeiro, para a manutenção do referido Centro.

Com a crescente demanda de crianças fora da escola, o referido Centro passou a oferecer as modalidades de Educação Infantil; I Segmento do Ensino Fundamental (de $1^{\mathrm{a}}$ e $4^{\mathrm{a}}$ séries) e Educação de Jovens e Adultos com $1^{\mathrm{a}}, 2^{\mathrm{a}}$ e $3^{\mathrm{a}}$ fases, atendendo 114 alunos. Somando-se a quantidade de alunos nas duas modalidades mencionadas em 2005 a escola atuou com 382 alunos. Assim surgiu a escola, mesmo sem ato legal de criação, passando a funcionar num prédio localizado em pista principal de um Conjunto Residencial de classe média alta, com amplo espaço livre e salas arejadas, sendo possível ainda a construção de novas salas pelo terreno que possui.

O prédio atual está construído em uma área ampla, mas somente dispõe de quatro salas de aulas bem arejadas e conservadas. Possui em suas dependências uma cozinha higienizada e bem equipada, sala de direção, secretaria e sala de professores conjugadas. Não dispõe de uma biblioteca apropriada para visitação e consulta de livros, além do que, há uma insatisfação coletiva por parte do(a)s aluno(a)s em relação ao pátio, pois o mesmo é descoberto, e ainda na areia, causando muito desconforto na época do inverno.

Tratando-se da sala de aula onde ocorreu a observação, a mesma não possuia ventiladores, porém, as janelas facilitavam a entrada da ventilação promovendo um ambiente fresco e agradável; a iluminação era 
adequada; as mesas e cadeiras sem conforto e sempre enfileiradas; as paredes revestidas com azulejos e ornamentadas com cartazes de trabalhos realizados pelas crianças e adolescentes do ensino fundamental diurno, não sendo verificado nenhuma produção dos alunos da EJA.

Em relação ao acervo bibliográfico destinada a EJA, a escola dispunha de 4 coleções de LDs, totalizando 96 livros, específicos para a modalidade de EJA; de 281 revistas - Presença Pedagógica e Nova Escola datadas de 2002 e 3 jornais do MEC; 10 dicionários de apoio e 280 em uso pelos alunos.

O quadro docente da escola na modalidade EJA era composto por quatro professoras, sendo duas delas Graduadas em Licenciatura, uma PósGraduada e uma formada no Magistério e cursando Graduação, na época.

\section{Os sujeitos}

A professora

A professora $\mathrm{S}$ declarou ter 36 anos de idade. É concursada do município há dez (10) anos e meio, desse tempo há dez (10) anos ensina na escola campo de pesquisa e há oito anos e meio (8a e 6 meses) trabalha com o Ensino Fundamental de EJA. Tem formação em nível superior em Pedagogia com Especialização em Psicopedagogia.

A professora entrevistada disse não ter um teórico específico que norteie a sua prática pedagógica, mas procura basear-se nos ensinamentos do educador Paulo Freire, pois o pesquisador na sua Pedagogia considera a leitura de mundo que o educando adulto traz para a sala de aula, reconhecendo no outro o direito de dizer sua palavra; mostrando como nós os educadores devemos respeitar os níveis de compreensão dos educandos. Menciona também Vygotsky pela sua contribuição em ver o ser humano no contexto social e capaz de desenvolver-se com os estímulos adequados. E em Emilia Ferreiro pela questão do método da base alfabética, pois no 
trabalho com $1^{\text {a }}$ fase (alfabetização) essa compreensão é de fundamental importância para o desenvolvimento do aluno.

Os(As) aluno(a)s

A sala observada era composta de 32 alunos matriculados na $1^{\text {a }}$ fase mantendo-se uma freqüência de 27 alunos por noite, numa faixa etária entre 22 a 58 anos de idade.

A maioria dos alunos residia próximo à escola, casados, mantendo uma família em média de dois a sete filhos, empregados e/ou subempregados sobrevivendo com uma renda baixa, nunca mais que o salário minimo. Apresentavam uma aparência cansada, pois, muitos vinham direto do trabalho. No entanto, apesar do aspecto enfadonho demonstravam o desejo de aprender.

Declararam em seus relatos que o maior motivo do retorno à escola foi a necessidade de aprender a ler e escrever por conta das exigências da própria sociedade. Outros declararam necessidades pessoais como motivos da preocupação em aprender a ler e a escrever.

\section{As representações da professora e dos alunos sobre o LD e sua utilização}

Procurou-se captar nas falas da professora entrevistada a forma como utiliza e a avaliação que faz dos LDs destinados a EJA existentes na escola, o papel dos mesmos na prática pedagógica e conseqüentemente no processo de ensino-aprendizagem em Língua Materna - LM - dos alunos jovens e adultos.

A professora entrevistada reconhece a importância da chegada dos livros na escola, faz uma comparação entre as práticas pedagógicas antes da existência dos LDs nas escolas e após a chegada dos LDs. Para ela sofria-se muito. 
[...] sem ter nada para trabalhar [...]. [...] comparando (o livro) como quando não tinha nada para trabalhar [...] só tinha o de ensino Fundamental, pra criança, que a gente sabia que não era assim que trabalhava, mas também não encontrava nenhuma opção”. Mas faz a análise crítica dos mesmos: “[...] Esses que têm agora, as opções são muito poucas, mas eles ajudam um pouco na sala de aula.

Sobre o LD de uma maneira geral a professora comentou que os temas apresentados são interessantes e bons de serem trabalhados, assim como os textos que os acompanham. Essa afirmação da professora decorre dos textos dos livros referidos, tratarem de temas que envolvem a realidade do aluno jovem e adulto.

Ao ser solicitada para comentar sobre o LD de LP das coleções para a EJA, a professora afirma que "os temas apresentados são interessantes e bons de serem trabalhados, assim como os textos que os acompanham. As atividades, porém, deixam muito a desejar, pois são muito repetitivas e muito tradicionais, trabalhando quase sempre com a formação de palavras”. Mesmo assim, espera que as coleções possam contribuir para o crescimento do aluno.

Essa fala da professora coincide com resultados de investigação anterior (SANTOS (coord.), 2004) mostrando que os temas propostos nos LDs relacionam-se ao contexto e ao cotidiano dos alunos. Por outro lado às questões de compreensão textual são, em sua maioria “[...] aquelas que sugerem atividades mecânicas de transcrição de palavras ou frases. Para tanto utilizam verbos como: copie, retire, aponte, indique, transcreva, complete assinale, identifique, dentre outros” (MARCUSCHI, 2001, p. 52).

Em relação à coleção de LDs adotado na escola, a professora investigada declara: “[...] especificamente aquele (livro) do NUPEP ${ }^{5}$

\footnotetext{
5 O material produzido pelo Núcleo de Ensino, Pesquisa e Extensão em Educação de Adultos e em Educação Popular do Centro de Educação da Universidade Federal de Pernambuco (NUPEP- UFPE) para a EJA é o resultado de uma experiência de cinco anos num Centro de Educação de Jovens e Adultos - CEJA, em Olinda Pernambuco. O mesmo foi elaborado para atender as necessidades básicas de aprendizagem de jovens e adultos
} 
olhando para as atividades praticamente são todas iguais [...]”. E diz ainda que:

as atividades do NUPEP são sempre assim, geralmente eles pedem pra escolher uma palavra do texto pra trabalhar, pra escrever, por exemplo: tinha uma que era trabalho, pra procurar em revistas e jornais palavras que contenham TRA, no começo, no meio ou no fim. Aí no outro texto, vem à mesma atividade, ora ele pede pra procurar na revista, ora ele pede para o aluno dizer e escrever.

Ao avaliar a coleção Educarte ${ }^{6}$ adotada na escola, a professora afirma não utilizar muito, primeiro porque eles estão mais voltados para a matemática e segundo porque os LDs são muito complexos, conforme suas palavras: "Educarte hoje é mais de Matemática o de Português eu não uso muito”.

Em relação aos textos do LD de LP a professora acrescenta “[...] Pra $1^{\text {a }}$ fase eles tem uns textos muitos longos [...]”. Quando a professora faz essa restrição à extensão do texto, ela estabelece um limite no uso de gêneros textuais que circulam na sociedade letrada e que os alunos têm contato permanente, além de subestimar a capacidade lingüística dos mesmos.

Por fim a professora afirma que a melhor coleção é a Viver, Aprender $^{7}$ “[...] Ele é o melhor [...]” “[...] Ele ajuda mais [...]”. À avaliação de que é a "melhor coleção", mesmo não tendo sido justificada pela professora, infere-se que tem como argumento principal o fato de ter sido

trabalhadores e contribuir na sua profissionalização, bem como na realização de processos de pesquisas educacionais e formação do seu professorado (SOUZA, 2001, p. 139-140).

${ }^{6}$ A Coleção Educarte é produzida pela Editora do mesmo nome. Inclui-se entre as editoras que disputam o mercado editorial de livros adquiridos com recursos governamentais com antigos e novos materiais didáticos para a EJA. Na sua coleção dispõe de dois livros destinados ao ensino de LM: Linguagem é Vida - Ensino Fundamental - séries iniciais, volumes I e II.

${ }^{7}$ A coleção Viver, Aprender surgiu após a extinção da Fundação Educar, na década de 1990, por encomenda do Governo Federal que disponibilizou recursos financeiros, do Fundo Nacional de Desenvolvimento da Educação (FNDE), para compra de materiais didáticos, destinados ao I Segmento do Ensino Fundamental da Educação de Jovens e Adultos. Essa coleção foi em sua primeira versão impressa e distribuída pelo MEC ou pelas secretarias municipais e estaduais em todo o Brasil. É composta de quatro livros, contendo internamente os módulos, onde se inserem as unidades temáticas. 
pensada e elaborada por pesquisadores e professores com conhecimento teórico e larga experiência na área de EJA. No entanto, estudo recente QUEIROZ (2004), mostra que a referida coleção Viver, Aprender, no que tange ao ensino da LM não o prioriza, tendo como carro chefe as Ciências da Sociedade e da Natureza, dispondo em cada módulo um bloco denominado: “Um Pouco Mais de Língua Portuguesa”.

Ao tratar da importância do LD de LP para a prática em sala de aula a professora considera que:

Ele é importante porque muitas vezes é o único material escrito sistematizado e seqüenciado que o aluno tem acesso fora da escola. É uma forma do aluno ter mais estímulo e despertar para conhecer outros tipos de leitura e de ter um compromisso maior com a escola (ao faltar uma aula o aluno, através do uso do livro, reconhece o que perdeu).

A professora reconhece que o LD contribui para o aprendizado da leitura e da escrita se os textos e as atividades nele contidas forem contextualizados e bem trabalhados; reconhece que os alunos gostam do livro, sentem-se importantes e valorizados com eles. No entanto considera o livro um elemento dispensável, pois (ela) tem acesso a outros recursos oferecidos pela escola: "Ele não é o único material escrito utilizado, sempre procuro complementar e dinamizar as aulas com outros recursos para que os alunos possam ampliar seus conhecimentos”.

Sobre o uso do LD de LP em sala de aula a professora comentou que escolhe os temas que sejam significativos para a turma. Trabalha com as atividades que considera adequadas e complementa com outras atividades que elabora. Utiliza o LD do aluno uma ou duas vezes por semana no máximo, procurando complementar e dinamizar as aulas com outros recursos para que eles possam ampliar seus conhecimentos. 
Quando a professora trabalha o LD em sala de aula ela o faz de forma que o aluno entenda a importância de se apropriar e fazer uso da linguagem do dia-a-dia, procurando utilizar outros materiais que possam contribuir para o aprendizado do aluno, fazendo uso de gêneros textuais receitas, musicas, imagens e rótulos - e suportes de gêneros - jornais. Atividades que contribuam para o desenvolvimento da expressão oral.

Ao proceder assim a professora reconhece que existem textos escritos que se situam, no contínuo, mais próximo ao pólo da fala conversacional (bilhetes, cartas familiares, textos de humor, por exemplo), ao passo que existem textos falados que mais se aproximam do pólo da escrita formal (conferências, entrevistas profissionais para altos cargos administrativos e outros), existindo, ainda, tipos mistos, além de muitos outros intermediários, lembra Koch (1997, p. 32).

A professora analisa que nem sempre os alunos reagem bem diante do uso do LD, necessitando de sua intervenção para romper os bloqueios surgidos: “[...] Às vezes têm alguma resistência, mas quando é proposta que vejo que não atende as suas necessidades faço algumas adaptações ou complemento com outras propostas”.

Contrariamente a afirmação da professora de que os alunos reagem ao LD, a maioria deles demonstra, através das falas, o gosto e o interesse pelo LD, conforme pode ser identificado no item abaixo.

\section{O uso do LD a partir dos alunos}

Ao serem abordados de como trabalham com o LD os alunos comentaram que aceitam o livro com bom gosto, que levam as atividades para fazer em casa e que queriam mesmo era "[...] ter um livro pra estudar, pra juntar as palavras, pra saber o que ta fazendo:" [...] o livro ensina tudo”.

Outro aluno ressalta que "É bom, é ótimo. O livro pra mim é ótimo”. 
Outro diz que “[...] é muito puxado”, justificando que "é porque tem muita leitura que a gente tem que pensar pra tirar da cabeça, pra copiar né, às vezes pra completar as respostas, pra gente que nunca sabe... aí é uma dificuldade, a gente quebra a cabeça um pouco, mas vai acertando, se tiver errado ela diz que ta errado, que vai até acertar”.

Quando perguntados sobre qual livro gostam mais, os alunos tiveram opiniões diferentes. Uns disseram gostar mais do livro de LP, outros de Matemática. A opção pelos LDs das duas áreas do conhecimento revela a importância que eles, e a sociedade como um todo, atribuem marcadamente ao aprendizado dos conteúdos das referidas áreas.

Quanto à utilização do $\mathrm{LD}$, os alunos disseram que o uso vai além da sala de aula, como afirma um deles: "Levo. Levo o livro pra casa, abro, olho, leio algumas palavras, não todas...”. Complementa outro aluno: “Eu leio o livro mais em casa do que na escola. Tenho umas horinhas vagas, aí eu pego mais. A escola ensina bem, entendeu, puxa, mas a gente em casa com paciência aprende as coisas com mais calma”.

A fala de um aluno vem referendar a afirmação da professora de não se limitar ao uso do LD em sala de aula: “[...] ela faz a tarefa, passa na máquina dela e traz as folhinhas pra gente escrever no caderno”.

Quando abordados se tinham outros tipos de livros em casa, um aluno respondeu que sim: "Existe. Na minha casa tem bastante”.

Um outro aluno revelou:

[...] por que os meus filhos estudam no $1^{\circ}$ ano, oitava, né, aí sempre tem um livro. Só que eles... é difícil eu pegar porque eu já não sei nada, aí fica mais difícil eu pegar, assim, da série muito alta pra eu ler, porque eu to começando agora, aí fica mais difícil, às vezes, eles me explicam: 'esse livro daqui é assim, assim...’ mas a minha leitura é tão pouca pra chegar ali, por que o livro é muito alto e eu não entendo de quase nada. 
Sobre o contato com outros suportes de gêneros textuais como, jornal e revistas, fora da escola, em casa ou no trabalho, apenas um dos alunos afirmou que tem contato; a maioria respondeu que não. Para estes o contato com esse tipo de suporte de gênero somente acontece na própria escola.

Os alunos falaram dos cuidados com o LD, um deles declarou: "Ah, o meu só vive comigo pra ninguém não pegar, só eu mesma, pra não rasgar”, outros referendaram a fala. Os alunos afirmaram ter cinco livros da coleção NUPEP. Quanto ao LD de Português, os alunos disseram não gostar das atividades que solicitam desenhos, como diz a fala de um aluno: "Eu tento fazer um desenho bonito, mas eu não consigo”.

\section{Constituição das interações em sala de aula com o uso do LD}

Tomou-se como base, na análise desse item as categorias interação e escrita. Interação essa que implica numa atitude responsiva ente autor/leitor, mediada sempre pela linguagem verbal e não-verbal (BAKHTIN, 1992), ou seja, entendida como processo que ocorre entre dois sujeitos interlocutores, que interagem através do signo ideológico - a palavra, objetivando pelo menos um sentido no acontecimento discursivo.

A escrita no sentido considerado por Marcuschi (2001, p. 32), que defende a visão do continuum fala-escrita, salientando que os gêneros textuais aparecem na perspectiva da fala e da escrita dentro desse continuum tipológico das práticas sociais de produção textual. Complementando esse sentido recorremos a Barzeman (2006, p. 59) que menciona:

[...] as formas de escrita como fenômenos históricos - criados e reconhecidos, mobilizados e fortalecidos dentro da mente de cada escritor e leitor em momentos sócio-históricos específicos, mas transmitidos na acumulação de texto. A experiência textual acumulada e socialmente constextualizada aumenta o repertório formal e o comando processual de cada escrito e leitor. 
Para que o LD apresentar acumulação de gêneros que Barzeman (op.cit) enfoca é necessário que seja concebido na perspectiva bakhtiniana defendida por (Nunes-Macedo et al., 2004, p.18), como: “[...] um enunciado que constitui um elo na cadeia de 'comunicação verbal' estabelecida por alunos e professores na sala de aula [...]”.

Ainda segundo Nunes-Macedo “[...] a análise das interações face a face que constituem o uso do livro didático pode ser fecunda para a compreensão dos processos de ensino e aprendizagem da leitura e da escrita” (idem, ibidem, p. 18). Ele transita entre aluno e professor, numa interação mediada pela linguagem que é constitutiva dos sujeitos e da consciência.

A fim de estabelecer uma visão geral dessa constituição, foi elaborado um mapeamento das ações dos participantes (professora e alunos) que envolveram a leitura e a escrita. Para isso, foi analisado o diário de sala (registro diário da prática em sala de aula) da professora e dos alunos, perfazendo um total de treze (13) atividades de letramento observadas, em aulas alternadas e apenas em uma (1) utilizado o LD, que neste texto tornouse nosso objeto de análise.

Nessa atividade com o LD, foi trabalhado o texto da música Carinhoso de Pixinguinha, retirada do livro de LP dos alunos - Módulo I, A Historicidade do ser humano, NUPPEP, lição: “Meus Amores, Minha História com o outro”, p. 55. O objetivo principal da professora era trabalhar em sala a letra da música, sua interpretação e a escrita de palavras.

Inicialmente a professora fez uma abordagem sobre o tema, levando os alunos à descontração, para então perguntar:

P: “o que é que vem na cabeça de vocês quando se fala em amor? 
Alunos: "muita alegria, gaia, amor de filho, mãe, neta, paixão, sofrimento, desgosto dos filhos, raiva”. Eles dizem que a música trata de uma história de amor entre um homem e uma mulher.

Da maneira como a professora procedeu nota-se que ela não tem clareza do que é um tema. Para Bakhtin (apud FREITAS, 1999, p. 128-9).

[...] O tema da enunciação é um sistema de signos dinâmico e complexos, que procura adaptar-se adequadamente às condições de um dado momento da evolução. O tema é a reação da consciência em devir ao ser em devir. A significação é um aparato técnico para a realização do tema [...].

Após conversarem sobre o tema, a professora coloca um Cd com a música. Os alunos cantam junto com a professora, fazendo uma interpretação da música. Depois ela solicitou que eles enumerassem as linhas do texto e fizessem uma leitura coletiva e em seguida uma atividade de escrita no livro. A professora trabalhou com apenas duas perguntas: “O que o autor diz sobre ele mesmo”? “O que ele diz sobre o seu coração?

Mas enquanto os alunos se organizavam para realizar a atividade ela continuava monologando: “Observe esta expressão: `E os meus olhos ficam sorrindo [...] . Podemos sorrir com os olhos fechados? Como? Em sua opinião, por que a pessoa amada pelo autor dessa música foge dele? Quais os motivos que levam uma pessoa a querer fugir do amor? Você já teve uma experiência?”. Nesse momento ficou explicito que a professora estava enfocando as questões de compreensão textual e até tentando extapolar.

Para responder as questões os alunos trabalharam em duplas, que é uma tentativa de interação com o outro. Um aluno perguntou se a palavra apaixonado se escreve com c, ch, ou x. A professora respondeu que se escreve com x. Perdendo assim a oportunidade de levar o aluno a uma reflexão do seu conflito em relação a escrita da palavra, sobretudo de 
explorar a questão da sonoridade das letras que se assemelham. O que requer um conhecimento de fonética.

Passado um tempo, a professora expressa a sua preocupação com a questão ortográfica, quando solicita que os alunos digam a letra das palavras que encontraram dificuldades e ela escreveria no quadro. Ao ditar as letras da palavra apaixonado, eles não consideram a letra i, a professora escreve como eles disseram: APAXONADO. Ela diz que alguém fez diferente, e que mesmo não pronunciando a letra i, ela existe. Como os alunos em processo de alfabetização utilizam muito a oralidade, a letra, não faz falta, na pronuncia da palavra. Isso acontece sobretudo, por que o aluno encontra-se na compreensão de que a escrita representa ainda fala.

Nesse sentido Abaurre (1991, p. 11-2), explica que as primeiras escritas dos alunos, em processo de alfabetização “[...] não são exemplos verdadeiros e próprios da língua escrita; eles podem ser definidos como escrita apenas no sentido de que foram realizados em espaço gráfico de uma página em branco. Sua estrutura preferencial é, todavia, a da linguagem oral”.

Dessa forma a professora perde outro momento importante de levar o grupo a um reflexão sobre o processo da escrita e age de forma mecânica. Para Bazerman (2006, p. 11) os estudantes são:

agentes, aprendendo a usar criativamente a escrita dentro das formas interacionais tipificadas, mas dinamicamente cambiantes que chamamos de gêneros, eles virão a entender o poder da escrita e serão motivados a fazer o trabalho árduo de aprender a escrever efetivamente.

A seguir, a professora convida os alunos para escreverem a palavra romântico no quadro. Uma aluna escreve ROMETIO, um aluno escreve ROMETIRO, outro ROMETICO, outro ROMANTETCU, e outro RAUNATEC. A professora ressalta que cada um escreveu de um jeito e 
diante disso ela pergunta qual é a primeira sílaba da palavra ROMANTICO, os alunos dizem que é RO. Ela pergunta se todos escreveram esta silaba ou se alguém fez diferente, eles dizem que tem um diferente, um RA, e que o certo é RO. A silaba MAN, apenas um aluno acerta, e vibra pelo acerto. A atividade tem prosseguimento com a silabação e após e a escrita correta da palavra ROMÂNTICO, a professora diz que todos acertaram um pouco.

Em seguida é a escrita da palavra VERDADEIRO, a professora acompanha os alunos de banca em banca, mesmo sem ser solicitada pelos alunos e diz que mesmo não sendo pronunciado a palavra tem a letra i. Um aluno diz que o $\mathbf{V E}$ é forte, que precisa de um $\mathbf{R}$, a professora concorda e diz que nesta palavra tem mais de um $\mathbf{R}$. Depois é a escrita da palavra SINCERO, após os alunos tentarem sozinhos, a professora perguntando as letras, escreve no quadro e explica SIN, é como no MAN (de ROMANTICO), os alunos logo entendem que precisam da letra $\mathbf{N}$.

Observou-se que mesmo tentando estabelecer uma interação dialógica simétrica com os alunos, a professora termina por isolar o texto e trabalhar somente com as palavras e fazer uso da silabação, não havendo um esforço da interação da leitura com a escrita. O que ocorreu foi uma predominância da forma tradicional, tão presente ainda nas salas da EJA. Essa modalidade trabalha com jovens e adultos que vão a escola para aumentar suas possibilidades de ter sucesso na vida e de contribuir com a sociedade. Para Bazerman (2006) é na sala de aula que os educadores de letramento têm oportunidades de trabalhar e contribuir para o crescimento e desenvolvimentos desses sujeitos.

O comportamento expresso pela professora, nos mostra que ela tenta avançar a forma metodológica e pedagógica de trabalhar, mas 
lingüisticamente ela enfocou a gramática pela gramática, na escrita das palavras.

Fica explicito que a professora tem dificuldades de trabalhar os gêneros textuais na perspectiva da fala e da escrita dentro de um continnum tipológico das práticas sociais de produção de texto concebidas por Marcuschi (2001), conforme demostrou na exploração das palavras retiradas do texto. Segundo Freitas (1999) sendo a palavra retirada do “estoque sígnico”, a qual circula em determinadas sociedades e em um dado momento, é detentora de formação ideológica, permitindo uma outra leitura (reação) por parte dos interlocutores. Assim, o autor (op. cit.) em suas observações, retrata a dinamicidade do signo enquanto palavra, de forma circundante entre as estruturas sociais em seu nível mais elementar - o da ideologia do cotidiano. O que não aconteceu na aula em análise.

Para compreender o sentido do campo descrito por Freitas, a análise do sistema ortográfico de escrita, utilizado pela professora, não teve um papel significativo no evento de letramento, bem como em outros, durante o período observado. O fato de a maior parte dos alunos dominarem o sistema alfabético de escrita pode justificar a ênfase na análise ortográfica. A leitura e a produção de textos não ocuparam um espaço nas aulas com ou sem o LD.

O gênero textual utilizado pela professora, no caso específico a música, não foi explorado. Segundo Brandão (2000, p. 25) esse gênero que circula no dominio discursivo artístico/literário, contém, muitas vezes, uma linguagem lírica, poética ressaltando, por conseguinte as competências sócio-cognitivas frente às diversidades e heterogeneidade, que apresenta. Quando os alunos sentem-se parte da vida de um gênero, qualquer um que atraia a sua atenção, o trabalho árduo e detalhista de escrever se torna irressistívelmente real, pois traz uma recompensa também, real quando engajado em atividades em que os alunos consideram importantes (BAZERMAN, 2006). 
A professora precisava perceber que gênero não é simplesmente uma categoria linguistica definida pelo arranjo estruturado de traços textuais. Ele é uma categoria sociopsicológica que se usa para reconhecer e construir ações tipificadas dentro de situações tipificadas. É uma maneira de criar ordem num mundo simbólico sempre fluído (BAZERMAN, idem).

Não ficou evidenciada também nessa aula uma articulação no evento de letramento a visão do continuum fala-escrita como fundamenta Marcuschi (2001). O foco permaneceu na dicotomia que ainda persiste entre a oralidade e a escrita:

[...] a) idéia de que a escrita codifica lexical e sintaticamente os conteúdos, enquanto que a fala usa os elementos paralíngüísticos como centrais; b) a idéia de que o texto escrito é mais coesivo e coerente do que o oral, sendo a fala fragmentária e sem conexão (ou com uma conexão marcadamente interacional); c) a noção de que a escrita conduz os sentidos diretamente a partir da página impressa, sendo que a fala se serve do contexto e das condições da relação face a face.[...]. (MARCUSCHI, idem, p. 29).

Na atividade acima explicitada, foi apresentada uma tentativa inicial de interação (entre professor/aluno, aluno/aluno), no entanto não avançou do uso do texto como pretexto para uso de objeto isolável, para análise gramatical. Quando o professor proporciona aos alunos apenas os elementos formais dos gêneros, está aprisonando-os a uma escravidão irreflitida às práticas correntes, sem dar-lhes meios que possam sobreviverem as mudanças, que ocorrerão nas suas vidas profissional e pessoal (BAZERMAN, op. cit.). 


\section{(In)conclusão}

Como principais (in)conclusões da investigação relacionam-se os seguintes pontos: Em primeiro lugar a professora, em alguns momentos, demonstrou comungar das mesmas concepções defendidas pelos teóricos referenciados. Em segundo lugar, demonstrou na prática pedagógica coerência com a sua fala em relação à utilização do LD. De um total de 13 aulas observadas, mesmo os alunos levando diariamente o LD para a sala de aula, apenas em um (1) evento presenciou-se o uso do LD. As observações revelaram que o uso do LD, não foi uma prática constante em sala de aula, mesmo considerando que atualmente na EJA, do municipio onde ocorreu a investigação, são adotados LDs, além de outras coleções que são disponibilizadas na sala de leitura para o uso do professor e do aluno. Em substituição ao LD outros suportes de gêneros como jornais e revistas marcaram presença, o que é bastante significativo.

Nos eventos observados, com e sem o uso do LD, pode-se notar que houve momentos de tentativas de interação verbal e diálogo entre professora-alunos, porém em um dos eventos a professora $S$ entrou em conflito com a concepção de linguagem até então apresentada ao trabalhar a escrita de forma silábica. Com esse comportamento ela assumiu a concepção de linguagem como expressão do pensamento (GERALDI, 2002). O estranhamento desse fato é que a professora além de ter uma larga experiência - oito anos e meio - no Ensino Fundamental de EJA, tinha participado de todos os eventos de formação oferecidos pela secretaria de educação do municipío investigado.

Os momentos de intertextualidade, no processo de escrita, tendo o LD e outros suportes de gêneros como mediadores, ficaram muito a desejar uma vez que a preocupação tanto do professora, quanto dos alunos, esteve sempre centrada no dialeto padrão, no escrever correto. O desprezo e até 
desrespeito pelo dialeto popular, foi observado em uma das ações de letramento em que foi trabalhado um texto produzido pelos alunos de outra escola. Ao fazer a leitura e comentário do texto os alunos criticaram a forma como estava escrito, apontando os erros ortográficos e solicitando a correção a partir da linguagem padrão.

Finalmente, comparando as ações de letramento observadas às contribuições dos autores consultados, é possível constatar que as abordagens da professora sobre interação na sala de aula, utilizando gêneros discursivos e tendo a fala-escrita como continuum apresentaram propostas que não contemplaram as categorias adotadas na pesquisa. Observou-se também, que não foi explorado e nem valorizado outras vozes presentes nos gêneros trabalhados, tanto do LD como de outros suportes, prejudicando assim, o entendimento ao enfoque bakhtiniano, fazendo com que a interação, e conseqüentemente a interação verbal, não acontecesse amplamente.

\section{Referências Bibliográficas}

ABAURE, Maria Bernadete (1991). O que revelam os textos espontâneos sobre a representação que faz a criança do objeto escrito. In: KATO, Mary (org.). A concepção da escrita pela criança. 2 ed. Campinas: Pontes.

BAKHTIN, Mikhail (2004). Marxismo e Filosofia da Linguagem. 11 ed. São Paulo: Hucitec.

BATISTA, Antônio Augusto G. et al (2002). Livros escolares de leitura: uma morfologia (1866-1956). Revista Brasileira de Educação. Maio/Jul/Ago. N $^{\circ} 20$.

BAZERMAN, Charles (2006). Gênero, agência e escrita. Hoffnagel, Judith Chambliss; Dionisio, Angela Paiva (Orgs). São Paulo: Cortez. 
BRAIT, Beth (org.) (2005). BAKHTIN conceitos-chave. São Paulo: Editora Contexto.

BRANDAO, Maria Helena Nagamine (org.). (2000). Gêneros do discurso na escola: mito, conto, cordel, discurso político, divulgação científica. São Paulo: Cortez. (Coleção Aprender e ensinar com textos; v. 5).

CHARLOT, Bernard (1983). A Mistificação Pedagógica. Realidades Sociais e Processos Ideológicos na Teoria da Educação. $2^{\mathrm{a}}$ ed. Tradução: Ruth Rissin Josef. Rio de Janeiro: Zahar Editores.

DIONÍSIO, Ângela Paiva e BEZERRA, Maria Auxiliadora (orgs) (2001). O livro didático de português: múltiplos olhares. Rio de Janeiro: Lucerna.

FREITAS, Antônio Francisco R. de (1999). O Diálogo em sala de aula: análise do discurso. Curitiba: HD Livros Editora.

FREITAS, Marinaide Lima de Queiroz (coord.) (2005). Relatório semestral de pesquisa FAPEAL, agosto, mime.

GERALDI, João Wanderlei (org.). et al (2002). O texto na sala de aula. Coleção na sala de aula. São Paulo: Ática.

GIL, Antonio Carlos (1991). Como Elaborar Projetos de Pesquisa. $3^{\text {a }}$ ed. - São Paulo: Atlas.

KOCH, Ingeadore (1997). Interferências da oralidade na aquisição da escrita. In: Trabalho de lingüística aplicada. Campinas, Unicamp, (30): 31-8.

MARCUSCHI, Luis Antônio (2001). Compreensão de textos: algumas reflexões. In: O livro didático de português: múltiplos olhares. DIONÍSIO, Ângela Paiva BEZERRA, Maria Auxiliadora (orgs.). Rio de Janeiro: Lucerna.

; SIGNORINI, Inês (2000). O ensino e a formação do professor: alfabetização de jovens e adultos. Porto Alegre: Artes Médicas Sul. 
MOURA, Tania Maria de Melo (1999). A prática pedagógica dos alfabetizadores de jovens e adultos: contribuições de Freire, Ferreiro e Vygotsky. $1^{\mathrm{a}}$ ed. Maceió: INEP: EDUFAL.

(2005). As diversidades culturais no Livro Didático da Educação de Jovens e Adultos. Anais do V Colóquio Internacional de Currículo. João Pessoa-Pb.

(2007). Metodologia do Ensino Superior: saberes e fazeres da/para a prática docente. Maceió: EDUFAL.

NUNES-MACEDO, Maria do Socorro; MORTIMER, Eduardo; GREEN, Juddith (2004). A constituição das interações em sala de aula e o uso do livro didático: análise de uma prática de letramento no primeiro ciclo. Revista Brasileira de Educação. Jan/Fev/Mar/Abr., $n^{0}$ 25. Associação Nacional de Pós-Graduação - ANPED; Rio de Janeiro: Autores Associados.

SANTOS, Maria Francisca Oliveira (coord.) (2003). A Importância dos Gêneros Discursivos no Ensino de Língua Portuguesa em Educação de Jovens e Adultos, no I Segmento do Ensino Fundamental do Sistema Público de Ensino na Cidade de Maceió. Relatório de Pesquisa. Fundação de Pesquisa do Estado de Alagoas - FAPEAL. Maceió, mime, agosto.

SANTOS, Maria Francisca Oliveira; QUEIROZ, Marinaide Lima de; MIGUEL, Geilda de Souza; MOURA, Tania Maria de Melo (2004). Gêneros Textuais na Educação de Jovens e Adultos. Maceió: FAPEAL/Recife: Editora Bagaço.

SOUZA, João Francisco de (2001). Material do NUPEP para a Educação de Jovens e Adultos. In: RIBEIRO, Vera Masagão (org.). Educação de Jovens e Adultos. Novos leitores, novas leituras. Campinas, SP: Mercado de Letras: Associação de Leitura do Brasil - ALB; São Paulo: Ação Educativa. (Coleção Leituras no Brasil).

ZILBERMAN, R. A leitura no Brasil: sua história e suas instituições. Disponível em http://www.unicamp.br/iel/memoria/Ensaios/regina.html. Acesso em 09 de abril de 2004. 


\section{Autoras:}

\section{Marinaide Lima de Queiroz Freitas}

Professora do Mestrado em Educação Brasileira da Universidade Federal de Alagoas. Vice-Líder do Grupo de Pesquisa Teorias e Práticas em Educação de Jovens e Adultos. Doutora em Lingüística.

naide12@hotmail.com

\section{Tania Maria de Moura}

Professora do Mestrado em Educação Brasileira da Universidade Federal de Alagoas. Líder do Grupo de Pesquisa Teorias e Práticas em Educação de Jovens e Adultos. Doutora em Educação.

tmmm09@hotmail.com

\section{Como citar este artigo:}

FREITAS, Marinaide Lima de Queiroz e MOURA, Tania Maria de. Processos interativos em sala de aula de jovens e adultos: a utilização do livro didático em questão. Revista ACOALFAplp: Acolhendo a Alfabetização nos Países de Língua portuguesa, São Paulo, ano 2, n. 4, 2008. Disponível em: <http://www.mocambras.org > e ou <http://www.acoalfaplp.org>. Publicado em: março 2008. 